\title{
THE EFFECT OF SETTING-UP OF ARTIFICIAL TEETH IN THE NEUTRAL ZONE ON EMG AND OCCLUSAL FORCE EQUILIBRATION IN MANDIBULAR TWO IMPLANT OVERDENTURES
}

\author{
Mohamed Abdel Hakim Abdel Aal*
}

\begin{abstract}
Purpose: This study was conducted to evaluate the effect of neutral zone concept on EMG $\& \%$ occlusal force distribution in mandibular implant overdentures.

Methodology: Twelve completely edentulous patients were selected from the out-patient clinic, Faculty of Dentistry, Beni-suef University. Patients were randomly divided into Group (I) \& (II) according to the way of artificial teeth set-up in the complete dentures. Group (I): Patients had received mandibular two implant overdenture constructed with the artificial teeth set-up over the crest of ridge. Group (II): Patients had received mandibular two implant overdenture constructed according to the neutral zone concept.
\end{abstract}

Two implants were installed in areas of mandibular canines according to the two stage surgical protocol. Ball attachments were inserted onto the implants after osseointegration. The previously constructed dentures were used for direct pick up procedures. Dentures of both groups were inserted into the patients' mouth.

Evaluation of EMG: Evaluation of EMG activity of the Masseter and Temporalis muscles was evaluated during clenching, chewing of soft food, chewing of hard food at denture insertion and one month after.

Evaluation of Occlusal force Equilibration: The \% of occlusal force distribution was evaluated for the dentures in the two studied groups with the aid of T-Scan device at insertion after occlusal adjustment by the articulating paper; two weeks after denture insertion and one month after T- scan analysis.

\section{Conclusions: Within the limitation of the present study the following was concluded}

Implant overdentures constructed with Neutral Zone concept may have better occlusal force distribution on the denture surfaces and better EMG records than dentures with the conventional set-up of teeth.

KEYWORDS: Neutral zone- EMG-Occlusal force distribution- Implant overdenture.

\footnotetext{
* Lecturer of Removable Prosthodontics, Faculty of Oral and Dental Medicine, Beni-Suef University.
} 


\section{INTRODUCTION}

Complete denture wearers may struggle to eat well with their dentures as their mandibular denture is almost unstable. Successful mandibular complete denture depends on sufficient stability and retention ${ }^{(1)}$. It was demonstrated that more than $50 \%$ of mandibular complete dentures have problems with retention and stability. ${ }^{(2)}$

Due to lack of retention and stability, the maximum biting force of complete denture wearers is diminished to about $20 \%$ from dentulous patients biting forces. The diminished biting force affects masticatory function; this will eventually lead to poor chewing ability in complete denture wearers. ${ }^{(3,4)}$

Mandibular dentures supported and retained by two implants are more superior to conventional dentures. ${ }^{(5)}$

Completely edentulous patients may be conveniently rehabilitated by two implant overdentures, placed in the inter-foraminal region. ${ }^{(6)}$

Long-term studies have confirmed that implant-supported overdentures provide satisfactory results with only two mandibular implants. ${ }^{(7,8,9)}$

It improves stability, retention, function and esthetics as well as preserves the residual ridge, especially in the mandible. ${ }^{(5)}$

The improvement of oral function may depend on the degree of retention and stability of the denture. ${ }^{(10,11)}$

Implant-stabilized overdentures increase maximum biting force, masticatory performance, improve patient satisfaction, and minimize pain during mastication. ${ }^{(12,13)}$

The activity of masseter muscle is significantly increased when implant attachments were used with overdentures. ${ }^{(14)}$

Moreover, the use of the neutral zone concept in denture construction improves the activity of mus- cles of mastication, mainly the masseter and temporalis muscles more than the conventional dentures because the neutral zone helps the physiologic adaptation of these dentures with the surrounding oral musculature contributing to their efficiency during mastication. ${ }^{(15)}$

Beresin and Schiesser, 2006, recommended that the artificial teeth should not be placed on the crest of the ridge or buccal or lingual to it, but should be placed as dictated by the musculature of each individual patient. ${ }^{(6)}$

Furthermore, the dentures fabricated with neutral zone approach achieve more stable retentive lower complete denture for patients with severely resorbed ridges and that correct positioning of posterior teeth allowed sufficient tongue space, and reduced food trapping adjacent to the molar teeth. ${ }^{(16)}$

Regardlessofimplantavailability,physiologically optimal denture contours and physiologically appropriate denture tooth arrangement should be achieved to maximize prosthesis stability, comfort, and function for patients. ${ }^{(8)}$

In addition, neutral zone technique is used to locate the optimal position for implants in cases of implant-supported overdentures, which enhances the overall outcome of implant treatment. As complete dentures and implant overdentures do not remain stable when improperly balanced forces are applied, the assessment of occlusal load distribution along the whole arch could be more relevant. ${ }^{(17)}$

Computerized and dynamic occlusal analysis system, such as T-scan are developed to measure occlusal load on multiple points in the dentition could be a suitable device that would not destabilize dentures during force recording. ${ }^{(18)}$

The system is able to record relative force with dynamic visual evaluation of a patient's occlusion from initial tooth contact to maximum intercuspation. ${ }^{(19)}$ 
T-Scan allows the prosthodontist to record certain parameters as bite length, distribution of occlusal load and the relative forces on the teeth ${ }^{(18)}$

From a biomechanical point of view, welldistributed occlusal forces over maximal denture bearing area coverage, minimizes the excessive concentration of stress, which may result in slower progression of RRR ${ }^{(20) \text {. }}$

Stress distribution prevents ischemia and bone resorption in residual ridge. Information regarding occlusal force distribution obtained from T-Scan is helpful to achieve centered and measurable occlusal force nearly $50 \%$ right $-50 \%$ left occlusal force balance improving the tissue adaptation of the dentures during mastication ${ }^{(21)}$

The use of T-Scan would aid in accurate occlusal analysis and corrections and can be demonstrated objectively. ${ }^{(18)}$

The present clinical study was conducted to evaluate the effect of using neutral zone concept on EMG activity of masticatory muscles and the \% of occlusal force distribution in patients rehabilitated with two implant retrained overdentures.

\section{Methodology :}

\section{Patient selection criteria:}

Twelve patients were selected from the outpatient clinic, Faculty of Dentistry, Beni-suef University according to the following criteria:

Completely edentulous maxillary and mandibular arches, moderately developed residual ridges, covered with firm and healthy mucosa, adequate crown height space ( $>12 \mathrm{~mm})$, Angle class I maxillo-mandibular relationships.

Patients with any systemic disease that might affect the neuro-muscular behavior and or implants osseointegration were excluded.

Patients were informed about the nature of the research work and signed written consents. Only motivated and cooperative patients were enrolled in the study.
Patients' Examination: Patients had undergone thorough extra-oral, intra-oral and radiographic examination. Diagnostic casts were mounted on a semi-adjustable articulator to evaluate the inter-arch space.

\section{Patients' Grouping:}

Patients were randomly divided into Group (I) and Group (II) according to the way of artificial teeth set-up in the complete implant overdentures.

Group (I): Patients had received mandibular two implant overdenture constructed with the artificial teeth set-up over the crest of ridge.

Group (II): Patients had received mandibular two implant overdenture constructed according to the neutral zone concept.

\section{Prosthetic Management:}

For Group (I): Patients had received complete dentures constructed according to the conventional procedures.

Group (II): Patients had received complete dentures constructed with the neutral zone concept as follows:

- 1ry impression, final impression and jaw relation record were made as the conventional protocol. After mounting of the master casts, the occlusion blocks were replaced by auto polymerized acrylic resin trial denture bases constructed on the mounted casts. Three stainless steel wire loops of $(1 \mathrm{~cm}$ in length, $2 \mathrm{~mm}$ in height and $0.9 \mathrm{~mm}$ gauge) were attached to the trial denture base in the anterior and the first molar areas over the crest of ridge to retain the molding material. fig (1)

- Low fusing modeling compound was softened and attached to the stainless steel wires of the maxillary trial denture base and the compound is trimmed and adjusted to give the proper lip support with the anterior and posterior plane running parallel to the inter-pupillary line and the Ala-tragus line respectively. 


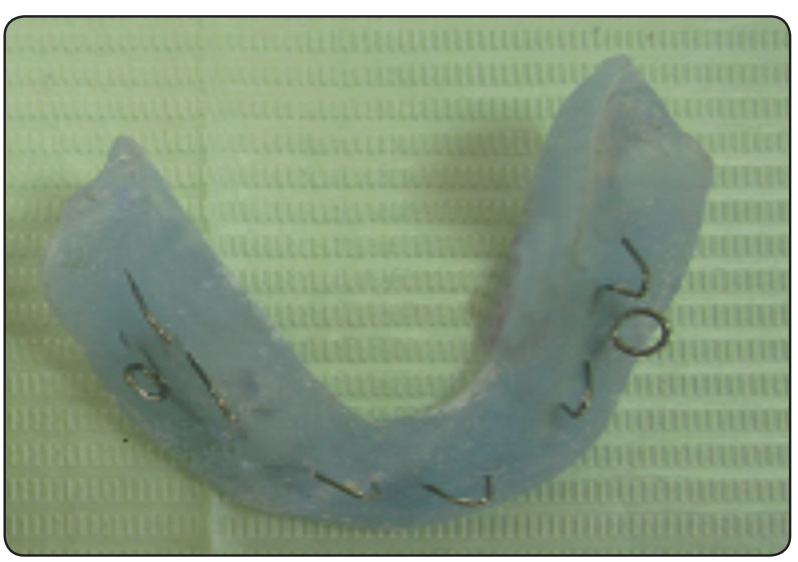

Fig (1) Stainless wire loops in the trial base

- Low fusing modeling compound was attached to the stainless steel wires of the mandibular trial denture base and adjusted at the pre-determined occlusal vertical dimension, while still soft it was inserted into the patients mouth with the adjusted upper occlusion block, the patient is asked to swallow and suck to mold the lower compound rim till recording the neutral zone, viscogel tissue conditioning material was added to the lower molded occlusion rim and inserted again in the patients mouth and the previous molding movements were made. fig (2)

- The lower occlusion block were then boxed and poured with plaster to produce the plaster indices used to guide the setting of the artificial teeth in the neutral zone.

- Try-in of the trial denture was made to check the position of the artificial teeth in relation to the neutral zone; the denture is then processed, finished, polished and was delivered to the patient.

\section{Implants Installation:}

The mandibular dentures were utilized as a scan appliance. CBCT scan were made for all patients. The mandibular dentures were duplicated into clear acrylic resin which would be modified to be used as a surgical guide.

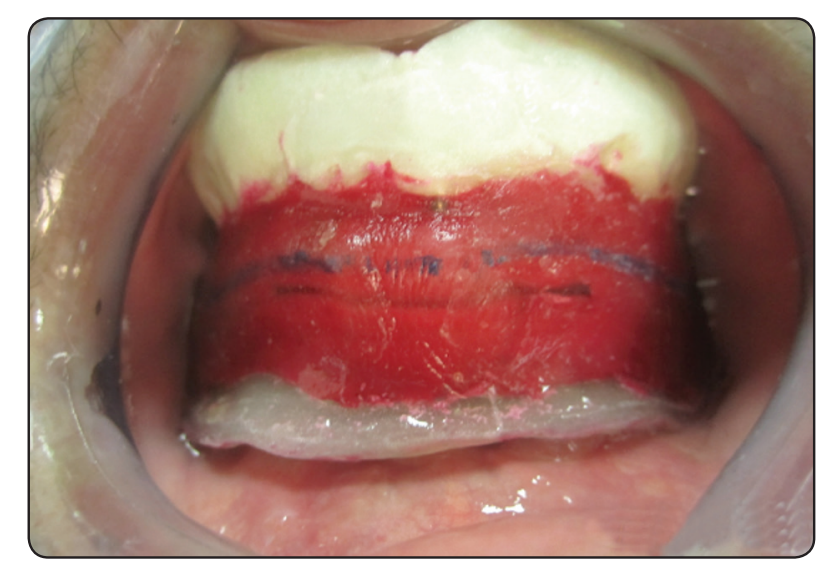

Fig (2) Viscogel neutral zone impression in patient's mouth

Surgical phase: Patients were given 4 capsules of $500 \mathrm{mg}$ Amoxicillin (Amoxil, Medical Union Pharmaceuticals (MUP), Egypt), and instructed to use chlorohexidine mouthwash (Hexitol, The Arab Drug Company ADCO, Egypt) two days before surgery. Two implants (Screw implant legacy1, implant direct, USA.) were installed in the mandibular canine areas. The mandibular denture was then relived and lined with tissue conditioning material to ensure comfortable and accurate fit. Patients were instructed to keep on soft diet for one week without denture removal, rinse their mouth with Chlorohexidine mouth wash twice daily for 2 weeks, and they were asked to take amoxicillin 500 mg Capsules and Ibuprufen $400 \mathrm{mg}$ tablets (Brufen, Kahira Pharm. \& Chem. Ind. Co., Egypt) every 8 hours for 5 days.

Prosthetic phase: Three-four months after surgery, patients had undergone $2^{\text {nd }}$ stage surgery to uncover the implants.

Healing collars were inserted onto the implants $\&$ left for one week to allow gingival contouring. After one week, the healing caps were removed and Ball attachments (Implant Direct Legacy ball abutment) were fitted onto the corresponding implants. The previously constructed mandibular denture was relived opposite to the implant areas to accommodate for Ball attachments. Pick up of the 
female part was done by injecting cold-cure resin (Rebaron. GC Corporation. Tokyo. Japan) into the relieved areas. Denture was inserted into the patient mouth \& patient was instructed to bite in maximum intercuspal position till complete polymerization of acrylic resin. Denture was then removed with the caps picked-up in its fitting surface, the plastic sleeves were removed and the denture was trimmed and polished and delivered to the patients. Fig (3).

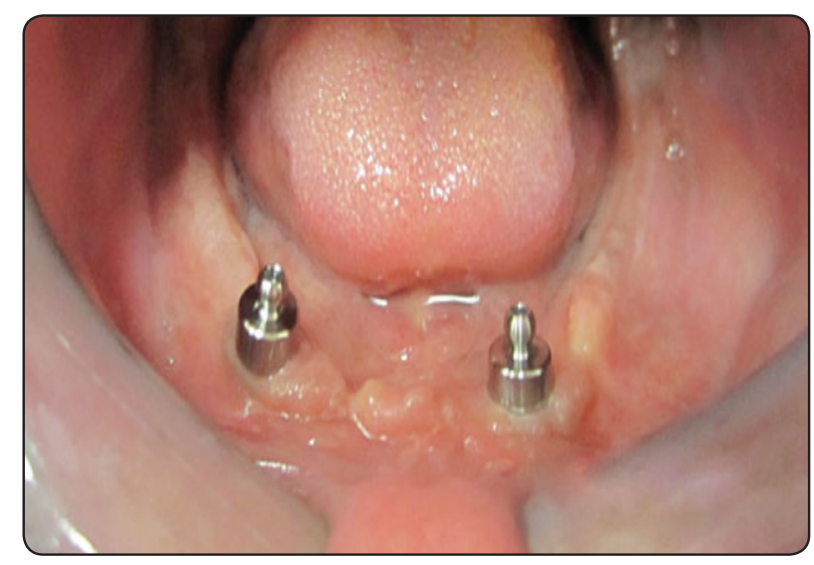

Fig. (3): Two ball attachments fitted onto implants.

\section{Evaluation of EMG:}

The electromyography muscle activity (EMG) of the masticatory muscles was evaluated with surface electrodes attached over each muscle bilaterally. A conducting material was applied onto the patient's skin of the face under the electrode. The patient was instructed to sit in a relaxed position on a comfortable chair with his head erected and constant throughout the EMG evaluation. Surface differential active electrodes were placed on the skin over the belly of Masseter Muscle and the anterior belly of the Temporalis muscles bilaterally. The positions of the electrodes were detected by palpation; the electrodes were fixed with adhesive tape, with the silver bars. fig (4).

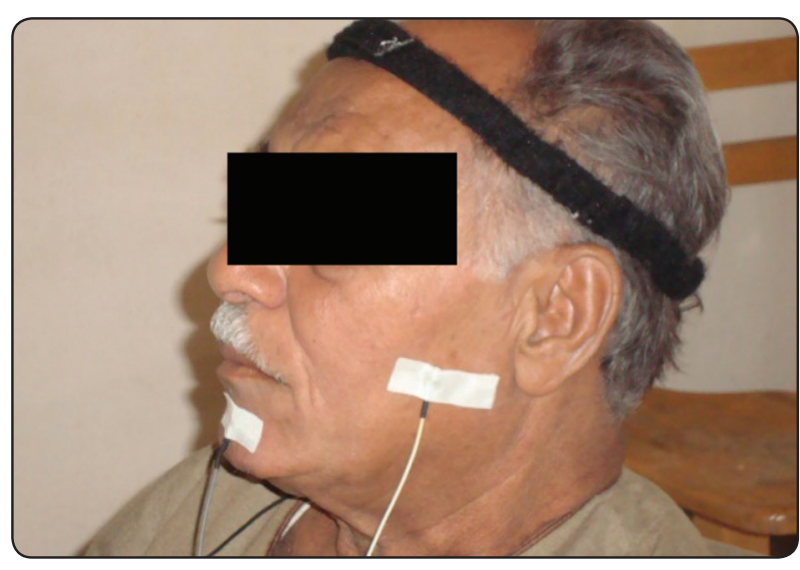

Fig (4) Electromyographic evaluation of the masseter muscle

Electromyographic Evaluation:

Evaluation of EMG activity of the masticatory muscles was evaluated during the following functions at the denture insertion \& one month after.

\section{1) Maximum clenching in centric occluding position}

\section{2) Chewing soft food "Banana"}

\section{3) Chewing hard food "carrot"}

Mean voltage values were calculated and saved for statistical analysis.

\section{Evaluation of Occlusal force Equilibration}

The dentures for patients of the two studied groups had undergone evaluation of occlusal force distribution with the aid of T-Scan device (Tekscan Inc., South Boston, MA, USA) at insertion after occlusal adjustment by the articulating paper , two weeks after denture insertion (before and after T-scan analysis) and one month after T- scan analysis as follows:

A sensor of a suitable size was selected according to the patients' arch size and form of dentures. The Patient was instructed to sit in upright position and the sensor was placed parallel to the occlusal plane of the maxillary denture \& the midline was marked between the central incisors. To adjust the 
sensitivity of the sensor; the patient was instructed to bite 2-4 times before recording. fig (5).

Patient was instructed to bite in maximal intercuspation with the sensor positioned between the upper \& lower dentures and to keep biting for 1-3 seconds according to the manufacturer instructions fig (5). The procedure was repeated three times and the movie of recording was saved on the computer for analysis. All measurements were made by one examiner. The percentage $(\%)$ of occlusal force distribution on the anterior and posterior denture areas were obtained for each quadrant fig (6). The mean values were calculated from the three recordings, \& the data was saved for statistical analysis.

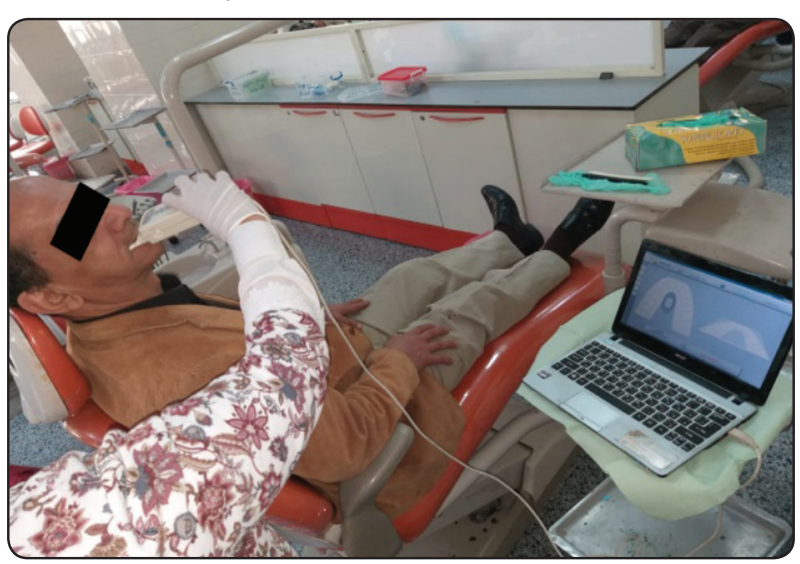

Fig (5) Patient biting on the sensor in maximal intercuspation

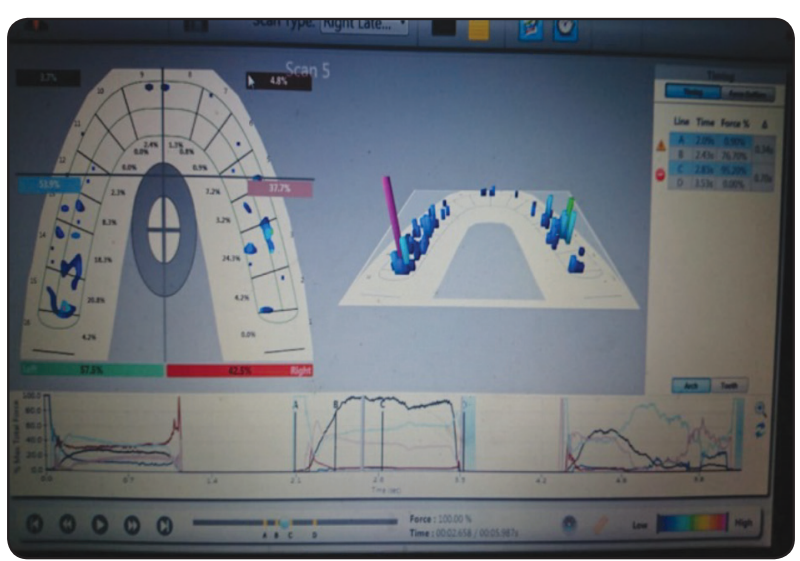

Fig (6) $\%$ of occlusal force distribution in the anterior and posterior areas of the overdenture as shown with T-scan device

\section{Statistical analysis}

Statistical analysis was performed with IBM SPSS Statistics for Windows, Version 23.0. Armonk, NY: IBM Corp. Student T test was used to compare between EMG results in the two groups while repeated measures ANOVA was used to test the effect of time within each group . Bonferroni's Post-hoc test was used for pair-wise comparisons when ANOVA test is significant. For occlusal analysis data were non-parametric, which called for Mann-Whitney U test to compare between the two groups. Friedman's test was used to study the changes within each group. Dunn's test was used for pair-wise comparisons when Friedman's test is significant. The significance level was set at $\mathrm{P} \leq 0.05$.

\section{RESULTS}

\section{EMG Activity of the Masticatory Muscles:}

Table (1\&2) is showing that the EMG activity of the Masseter and Temporalis muscles had recorded a statistically significant increase throughout the follow-up intervals in the two studied groups under clenching, eating soft and hard foods.

\section{Regarding the Occlusal force distribution:}

\section{The \% of occlusal force distribution in the anterior area}

The results of this study had revealed that there was a statistically significant decrease in \% occlusal force distribution in the anterior area of the dentures by time in group I \& group II. Moreover, there was a significant decrease in $\%$ occlusion force after $\mathrm{T}$-scan analysis and occlusal equilibration with a significant difference $\mathrm{p}<0.0001$.

Pair-wise comparisons between the follow-up intervals revealed that there was statistically nonsignificant change in $\%$ occlusal force two weeks after dentures' insertion $(\mathrm{P}<0.001)$ 
TABLE (1): Effect of time and group for temporalis muscle

\begin{tabular}{|c|c|c|c|c|}
\hline $\begin{array}{l}\text { Muscle } \\
\text { Activity }\end{array}$ & Time & $\begin{array}{c}\text { Group I } \\
\text { Mean + SD }\end{array}$ & $\begin{array}{c}\text { Group II } \\
\text { Mean + SD }\end{array}$ & P-value \\
\hline \multirow{3}{*}{ Clenching } & $\begin{array}{c}\text { At } \\
\text { insertion }\end{array}$ & $\begin{array}{c}0.593= \\
0.079\end{array}$ & $\begin{array}{c}0.502= \\
0.061\end{array}$ & $0.034 *$ \\
\hline & $\begin{array}{l}\text { after1 } \\
\text { month }\end{array}$ & $\begin{array}{c}0.677 \\
=0.061\end{array}$ & $\begin{array}{c}0.563= \\
0.068\end{array}$ & $0.005^{*}$ \\
\hline & P-Value & $0.002 *$ & $0.020^{*}$ & \\
\hline \multirow{3}{*}{ Soft food } & $\begin{array}{c}\text { At } \\
\text { insertion }\end{array}$ & $0.56=0.102$ & $\begin{array}{c}0.502= \\
0.061\end{array}$ & 0.062 \\
\hline & $\begin{array}{l}\text { After } 1 \\
\text { month }\end{array}$ & $\begin{array}{c}0.656= \\
0.078\end{array}$ & $\begin{array}{c}0.518= \\
0.063\end{array}$ & $0.001 *$ \\
\hline & P-Value & $0.001 *$ & 0.135 & \\
\hline \multirow{3}{*}{ Hard food } & $\begin{array}{c}\text { At } \\
\text { insertion }\end{array}$ & $\begin{array}{c}0.644= \\
0.049\end{array}$ & $\begin{array}{c}0.557= \\
0.042\end{array}$ & $0.042 *$ \\
\hline & $\begin{array}{l}\text { After } 1 \\
\text { month }\end{array}$ & $\begin{array}{c}0.708= \\
0.041\end{array}$ & $\begin{array}{c}0.623= \\
0.030\end{array}$ & $0.030^{*}$ \\
\hline & P-Value & $0.015^{*}$ & $0.013 *$ & \\
\hline
\end{tabular}

The \% of occlusal force distribution in the posterior area

At the right and the left posterior areas: In Group (I): The \% occlusal force in the posterior right areas of the dentures are decreased after occlusal adjustment \& T-scan analysis (2 weeks-1 month interval) with non- significant difference $(\mathrm{P}=0.060)$. However, the mean value of Occlusal force $\%$ in the posterior left areas had increased
Table (2): Effect of time and group for masseter muscle

\begin{tabular}{|c|c|c|c|c|}
\hline $\begin{array}{l}\text { Muscle } \\
\text { Activity }\end{array}$ & Time & $\begin{array}{c}\text { Group -I } \\
\text { Mean }+ \\
\text { SD }\end{array}$ & $\begin{array}{c}\text { Group- II } \\
\text { Mean }+ \\
\text { SD }\end{array}$ & $P$-value \\
\hline \multirow{3}{*}{ 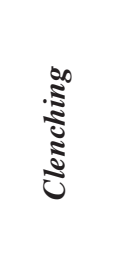 } & $\begin{array}{c}\text { At } \\
\text { insertion }\end{array}$ & $\begin{array}{c}0.59= \\
0.087\end{array}$ & $\begin{array}{c}0.526= \\
0.038\end{array}$ & 0.104 \\
\hline & $\begin{array}{l}\text { After1 } \\
\text { month }\end{array}$ & $\begin{array}{c}0.621= \\
0.089\end{array}$ & $\begin{array}{c}0.576= \\
0.056\end{array}$ & 0.203 \\
\hline & P-Value & 0.157 & $0.025^{*}$ & \\
\hline \multirow{3}{*}{$\frac{5}{5}$} & $\begin{array}{c}\text { At } \\
\text { insertion }\end{array}$ & $\begin{array}{c}0.567= \\
0.081\end{array}$ & $\begin{array}{c}0.478= \\
0.053\end{array}$ & $0.026^{*}$ \\
\hline & $\begin{array}{l}\text { After } 1 \\
\text { month }\end{array}$ & $\begin{array}{c}0.657= \\
0.059\end{array}$ & $\begin{array}{c}0.535= \\
0.064\end{array}$ & $0.001 *$ \\
\hline & P-Value & $0.001 *$ & $0.012^{*}$ & \\
\hline \multirow{3}{*}{$\frac{\sqrt{7}}{5}$} & $\begin{array}{c}\text { At } \\
\text { insertion }\end{array}$ & $\begin{array}{c}0.641= \\
0.081\end{array}$ & $\begin{array}{c}0.558= \\
0.027\end{array}$ & $0.0037 *$ \\
\hline & $\begin{array}{l}\text { After } 1 \\
\text { month }\end{array}$ & $\begin{array}{c}0.738= \\
0.035\end{array}$ & $\begin{array}{c}0.615= \\
0.031\end{array}$ & $0.001 *$ \\
\hline & P-Value & 0.412 & 0.191 & \\
\hline
\end{tabular}

*: Significant at $P \leq 0.05$

after correction with non- significant difference $(\mathrm{P}=0.978)$

On the other hand in Group (II): The \% occlusal force distribution in the right areas of the dentures had insignificantly increased after T- scan analysis \& occlusal force equilibration with $\mathrm{P}$ - value $=0.978$. The mean value of $\%$ occlusal force in the posterior left side areas had been decreased after correction with non- significant difference $(\mathrm{P}=0.320)$. 
TABLE (3): Effect of time and group on \%occlusal forces distribution

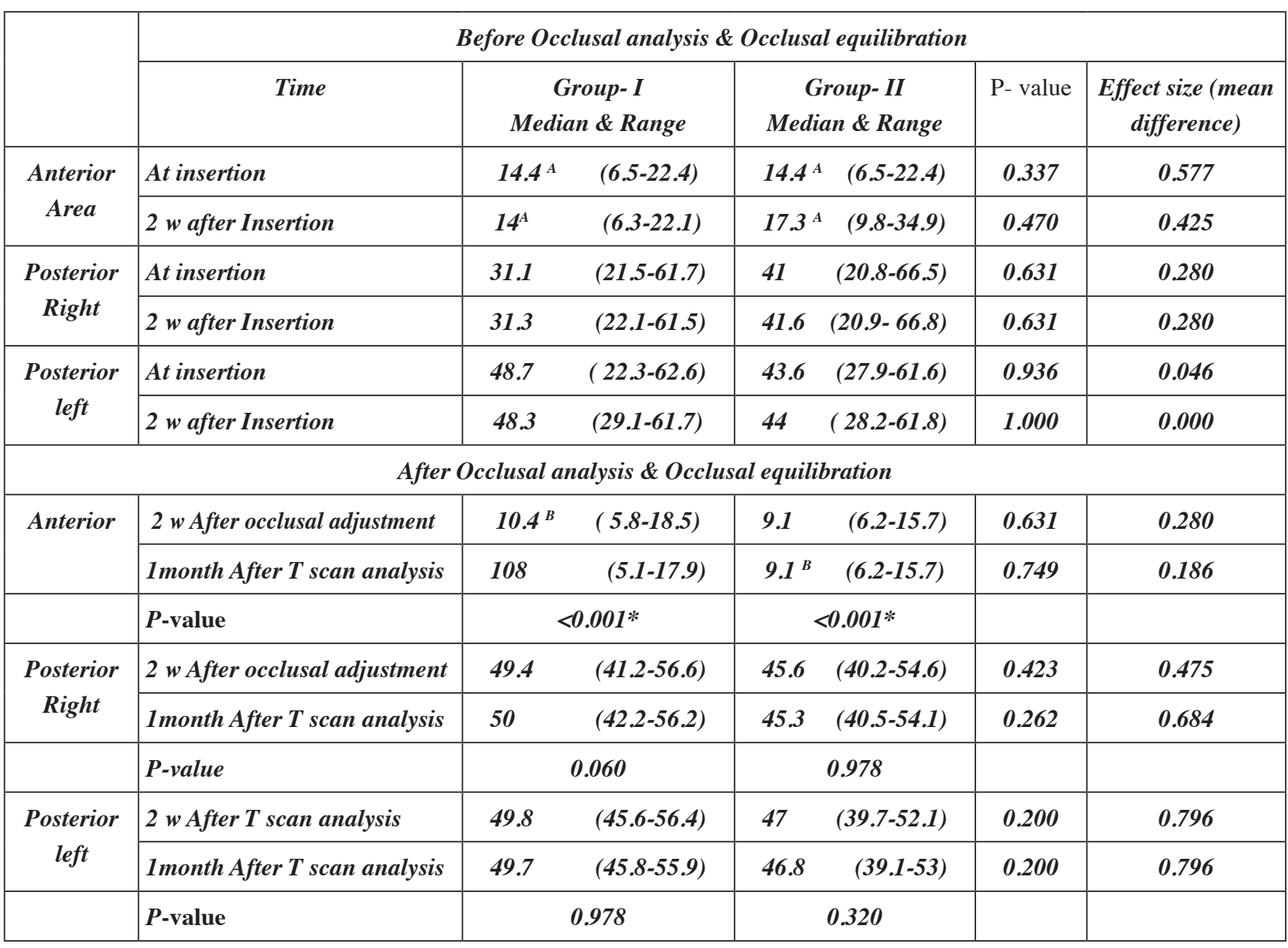

*: Significant at $P \leq 0.05$, Different superscripts in the same column are statistically significantly different

${ }_{A, B}^{A}:$ Effect sizes with similar letters are statistically insignificant

\section{DISCUSSION}

All patients enrolled in this study were satisfied with their implant overdentures.

The results of this study had revealed that the EMG activity of the masticatory muscles had increased gradually after implant overdenture insertion along the follow up period in the two study groups.

This finding agree with (Owen et al, 2002) ${ }^{(22)}$ who reported that implant supported over-dentures provide a sufficient number of dental contacts allowing stable reference for the contraction of masticatory muscles during static "clenching" and dynamic "chewing soft and hard food" activities, also Toman et al 2012, ${ }^{(23)}$ reported that implantsupported overdentures shows significantly higher EMG values of masticatory muscles than those of conventional dentures. This finding may be due to the presence of implant/attachment systems that stabilize the overdenture and allow the patients to exert higher biting force during function (24).

Masseter muscle records was significantly higher than the temporalis muscle during chewing hard food, soft food stuffs and clenching in the two studied groups. 
This might be due to the greater influence of the masseter muscle on the overdentures during chewing \& clenching than the temporalis muscle.

The results revealed that the muscle activity of the masseter and temporalis muscles was higher during chewing hard food than soft food stuffs. This may be explained as the hard food requires greater effort of the muscles to crush the food and to prepare it for swallowing. On the other hand; soft food requires less effort to perform the same function.

Consequently, the muscles consumed more energy during chewing hard food which increased the voltage amplitude of the action potentials on the electromyogram ${ }^{(25)}$ who concluded that the muscle activity depends on the food texture.

The values of EMG of masseter \& temporalis muscles were significantly higher in Group (II) than Group (I), this may be due to the better stability and retention of the overdentures constructed with the neutral zone concept that allowed more stable occlusion and improved patient satisfaction with their dentures ${ }^{(26,27)}$.

The neutral zone concept allows the construction of a complete denture so as to be in a state of "muscle balance" in harmony with its surroundings and with the normal neuromuscular function. ${ }^{(16)}$. The teeth will not interfere with the normal muscular function and second, the forces exerted by the musculature against the dentures are more favorable for stability and retention.

The $\%$ occlusal force distribution over the dentures was evaluated digitally with the aid of Tscan device in the two studied groups. The results had revealed that the \% of occlusal force was not balanced on the anterior, right $\&$ left sides of the implant overdentures in group I \& II at the first visit. (After occlusal adjustment with the aid of articulating paper) and two weeks later.

Also there was a statistically significant difference in the $\%$ of force distribution between right \& left sides in the two studied groups. This may be attributed to the insufficient accuracy of articulating papers \& laboratory remounting techniques to minimize the premature occlusal contacts and to produce bilateral balanced occlusal contacts.

As shown in Table (3); better occlusal force distribution was recorded in the two studied groups after occlusal adjustment with the aid of T- Scan device and patient's neuromuscular adaptation to their implant overdentures.

This finding may be due to the accuracy of T-scan analysis which allowed better evaluation of occlusal force distribution and determination of hidden premature occlusal contacts that couldn't be detected by articulating paper due to mucosal resiliency. Leading to better force distribution patterns on the right and left sides after occlusal corrections and decreasing the anterior share of occlusal load.

Moreover, Group (neutral zone) had shown significant better occlusal force distribution in the anterior and posterior areas of the dentures. This may be due to setting-up of the teeth in the neutral zone area that allowed the dentures to be in the areas of muscle balance with less premature occlusal contacts.

Table (3) is showing comparison between the two studied groups before and after occlusal analysis and equilibration; there was a significantly less \% occlusal force in group (II) than group (I) in anterior area. This may be due to the better stability of the neutral zone overdentures than those constructed with traditional technique.

Moreover, statistically non -significant difference in equilibration of force on the right $\&$ left sides after T- scan analysis and occlusion adjustment was noticed in Group (II) than Group (I) dentures. This may be explained by the proper positioning of the artificial teeth in the neutral zone area of each individual which is consistent with his muscles allowing better overdenture stability and less premature 
occlusal contacts and consequently better distribution of occlusal forces on the anterior and posterior areas of the dentures.

\section{REFERENCES}

1- Yen H, Chen M, Lin H, Ku S, Juan P, Llao P. Implant retained overdenture improves the retention and stability by using a locator system in a mandibular edentulous patient :A case report. Journal of prosthodontics and implantology.2013;2:26-30.

2- Redford M, Drury TF, Kingman A, Brown LJ. Denture use and the technical quality of dental prostheses among persons 18-74 years of age: United States, 1988-1991. Journal of dental research. 1996; 75 Spec No: 714-25.

3- Bakke M, Holm B, Gotfredsen K. Masticatory function and patient satisfaction with implant-supported mandibular overdentures: A prospective 5-year study. Int J Prosthodont 2002; 15:575-81.

4- Boven GC, Raghoebar GM, Vissink A, Meijer HJ. Improving masticatory performance, bite force, nutritional state and patient's satisfaction with implant overdentures: A systematic review of the literature. J Oral Rehabil 2015;42:220-33..

5- Sadowsky SJ. Mandibular implant-retained overdentures: a litera- ture review. The Journal of prosthetic dentistry. 2001; 86: 468-73.

6- Beresin, V.E. and Schiesser, F.J.: The neutral zone in complete dentures. J. Prosthet. Dent. 95: 93-100, 2006.

7- Meijer HJ, Raghoebar GM, Van't Hof MA. Comparison of implant-retained mandibular overdentures and conventional complete dentures: A-10 year prospective study of clinical aspects and patient satisfaction. Int J Oral Maxillofac Implants 2003;18:879-85.

8- Meijer HJ, Raghoebar GM, Batenburg RH, Visser A, Vissink A. Mandibular overdentures supported by two or four endosseous implants: A 10-year clinical trial. Clin Oral Implants Res 2009;20:722-8.

9 - Cune M, Burgers M, van Kampen F, de Putter C, van der Bilt A. Mandibular overdentures retained by two implants: 10-year results from a crossover clinical trial comparing ball-socket and bar-clip attachments. Int $\mathrm{J}$ Prosthodont 2010;23:310-7.

10- Van Kampen, F. M., A. van der Bilt, M. S. Cune, F. A. Fontijn-Tekamp and F. Bosman (2004). "Masticatory function with implant-supported overdentures.” J Dent Res 83(9): 708-711.

11- Van der Bilt A, Van Kampen FM, Cune MS. Masticatory function with mandibular implant-supported overdentures fitted with different attachment types. Eur. J. Oral Sci. 2006; 114:191-6.

12- Diaz-Tay, J., Jayasinghe, N., Lucas, P.W., McCallum, J.C. \& Jones, J.T. (1991) Association between surface electromyography of human jaw-closing muscle and quantified food breakdown.

13- Slagter, A.P., Bosman, F., van der Glas, H.W. \& van der Bilt, A. (1993) Human jaw-elevator muscle activity and food comminution in the dentate and edentulous state. Archives of Oral Biology 38: 195-205.

14- Bakke M, Holm B, Gotfredsen K. Masticatory function and patient satisfaction with implant-supported mandibular overdentures: a prospective 5-year study. Int. J. Prosthodont. 2002; 15:575-581.

15- Eskander A.E.: An electromyographic study on the effect of recording the neutral zone on muscular activity in complete denture wearers. M.D. Thesis. Cairo University, 1994.

16- Gaban M.J. and Walmsley A.D.: The neutral zone impression revisited. Br. Dent. J. 198.269-272,2005.

17- Jum'ah.A.A and Nixon.P.J. Neutral Zone in Complete Dentures: Systematic Analysis of Evidence and Technique. Smile Dental Journal I Volume 6, Issue 4 - 2011.

18- Cartagena AG, Sequeros OG, Garcia VG. Analysis of two methods for occlusal contact registration with the T-Scan system. J Oral Rehabil. 1997;24:426-432

19- Olivieri F, Kang K-H, Hirayama H, Maness WL. New method for analyzing complete denture occlusion using the center of force concept: a clinical report. J Prosthet Dent. 1998;80:519-523.

20- Tallgren A; Lang B.R; Holden S; Huyser D.J and Miller RL: Longitudinal Electromyographic Study of Chewing Patterns in Complete Denture Wearers. Int J.Prosthodontics 1992; 5: 415.

21- Maruo Y, Nishigawa G, Irie M, Oka M, Hara T, Suzuki K et al. Stress distribution prevents ischaemia and bone resorption in residual ridge. Arch Oral Biol. 2010;55:873-878.

22-Owens S1, Buschang PH, Throckmorton GS, Palmer L, English J. Masticatory performance and areas of occlu- 
sal contact and near contact in subjects with normal occlusion and malocclusion. American Journal of Orthodontics and Dentofacial Orthopedics, 121: P. 602-609, 2002.

23-Toman, M., Toksavul, S., Sarac_o_glu, A., Cura, C. \&Hatipo_glu, A. (2012) Masticatory performance and mandibular movement patterns of patients with natural dentitions, complete dentures, and implant-supported overdentures. International Journal of Prosthodontics 25: 135-137.

24- Fontijn-Tekamp, F.A., Slagter, A.P., van’t Hof,M.A., Kalk, W. \& Jansen, J.A. (2001) Pain andinstability during biting with mandibularimplant-retained overdentures. Clinical Oral Implants Research 12: 46-51.
25- Van der Bilt, A., M. Burgers, F.M. van Kampen, et at, Mandibular implant-supported overdentures and oral function. Clin Oral Implants Res, 2010. 21(11): p. 1209-13.

26- Feine, J.S. \& Lund, J.P. (2006) Measuring chewing ability in randomized controlled trials with edentulous populations wearing implant prostheses. Journal of Oral Rehabilitation 33: 301-308.

27- Fueki, K., Kimoto, K., Ogawa, T. \& Garrett, N.R. (2007) Effect of implant-supported or retained dentures on masticatory performance: a systematic review. Journal of Prosthetic Dentistry 98: 470-477. 